Schematic Support increases Memory Strategy Use in Young and Older Adults

\author{
Jack M. Kuhns and Dayna R. Touron \\ University of North Carolina at Greensboro
}

\author{
IN PRESS: \\ PSYCHOLOGY AND AGING
}

(C) 2019, American Psychological Association. This paper is not the copy of record and may not exactly replicate the final, authoritative version of the article. Please do not copy or cite without authors' permission. The final article will be available, upon publication, via its DOI: $10.1037 /$ pag0000433

Author Note:

Jack M. Kuhns, Department of Psychology, University of North Carolina at Greensboro; Dayna R. Touron, Department of Psychology, University of North Carolina at Greensboro. We thank Tim Alexander for help with experiment programming, Alexis Money, Samiat Olusesi, Talyah Simmons for help with data collection. We'd also like to thank Gail Corneau, Peter Delaney, and 
Paul Silvia for valuable comments on the manuscript. Portions of this research were presented at the 2017 annual meeting of the Psychonomic Society in Vancouver, British Columbia, and the 2018 Cognitive Aging Conference in Atlanta, Georgia. Data and analysis scripts for the project can be found at https://osf.io/4vm6c/. 


\begin{abstract}
During learning, a shift in processing often occurs with increased task experience, where initial slow, algorithmic processing proceeds into fast, retrieval-based processing. Older adults are slower than young adults in the rate at which this shift occurs, in part due a reluctance to use a retrieval strategy. The present research employed task materials that alleviate age-related differences in associative memory so that participants could rely on prior knowledge, or schematic support. The goal was to determine whether older adults' retrieval reluctance is due to a general avoidance of using the retrieval strategy or to low confidence in their memory for unfamiliar task materials. Participants completed two learning tasks: the Noun-Pair Lookup Task, where task materials consist of unrelated noun pairs, and an isomorph, the Grocery-Price Look Task, where task materials were grocery-items and prices. In this second task, the prices were either market-priced and consistent with everyday experience or were overpriced. Older adults were retrieval reluctant in the Noun-Pair Lookup Task, replicating previous findings. Stark condition differences were found in the Grocery-Price Lookup Task; older adults shifted much sooner for market-priced materials than for overpriced materials, and young adults shifted much later than expected for overpriced materials, where their final levels of learning were inconsistent with their memory use. Condition differences in retrieval use were substantially larger than the differences in retrieval accuracy. These results imply that confidence in using the retrieval strategy matters for both young and older adults, and that retrieval reluctance is not solely an age-related phenomenon.
\end{abstract}

Keywords: aging, learning, schematic support, skill, strategy choice, strategy execution 


\section{Schematic Support increases Memory Strategy Use in Young and Older Adults}

How do our skills improve as we practice them? Research has shown that changes occur in the mode of processing as we gain task experience (Anderson, 1982; Bryan \& Harter, 1897; Fitts \& Posner, 1967). This change is often a transition from algorithmic processing (e.g., computing steps in arithmetic) to retrieval from memory (Logan, 1988; Rickard, 1997). The present work considers factors influencing the shift in processing from an algorithm to retrieval strategy in young and older adults.

Older adults have been shown to avoid using a retrieval strategy despite adequate itemknowledge to do so (Touron \& Hertzog, 2004b). In this article we address one explanation for this avoidance: the associative content of the material being learned. Our approach to the problem is motivated by a dominant memory framework in cognitive aging - the associative deficit hypothesis (Naveh-Benjamin, 2000). Older adults' associative memory has consistently been found to be worse than that of young adults for pairs of items with no relational link; older adults' memory is often found to be equivalent to that of young adults' when the pairs are related (Castel, 2005; see Old \& Naveh-Benjamin, 2008 for a review and meta-analysis).

Studies of learning in older adults have often used unrelated and novel associative material (e.g., Cerella, Onyper, \& Hoyer, 2006; Frank, Touron \& Hertzog, 2013; Rogers, Hertzog, \& Fisk, 2000; Touron \& Hertzog, 2004a; Touron \& Hertzog, 2009). In the current study, we instead used materials that allow participants to rely on schematic support, or existing knowledge that gives a basis for organizational encoding strategies and retrieval cues (Castel, 2005; Craik \& Bosman, 1992). Given schematic support, older adults may feel more confident in their ability to learn the paired associates and subsequently shift to retrieval sooner than when not provided schematic support. In our novel version of the Noun-Pair Lookup Task (Ackerman 
\& Woltz, 1994), the Grocery-Price Lookup Task, successful performance entails learning to associate pairs of grocery-items and prices, the prices being either market-priced and consistent with everyday experience, or overpriced and inconsistent with prior everyday experience.

The predominant factor leading to improvement in skill learning tasks is experience with the task (Logan, 1988; Rickard, 1997; Schunn, Reder, Nhouyvanisvong, Richards, \& Stroffolino, 1997; Tenison \& Anderson, 2015). Theoretical explanations of how task experience impacts performance differ primarily on the assumed cognitive architecture and how best to model quantitative and qualitative changes in performance (e.g., Delaney, Reder, Staszewski, \& Ritter, 1997). A shared assumption among these models is that different strategies are executed at different stages of task experience, contingent on the amount of practice with the task. While some theories may assume that a strategy choice is made on the outset of a given trial (Rickard, 1997; Schunn et al., 1997; Tenison \& Anderson, 2015), their models only account for the amount of practice, remaining agnostic to whether top-down factors affect strategy choice.

Work examining learning in older adults has challenged existing theories, as older adults' strategy choices often do not follow from model predictions (Frank et al., 2013; Hertzog \& Touron, 2011; Hertzog, Touron, \& Hines, 2007; Hines, Hertzog, \& Touron, 2011; Lamson \& Rogers, 2008; Rawson \& Touron, 2009, 2015; Rogers \& Gilbert, 1997; Rogers, Hertzog, \& Fisk, 2000; Touron, 2006; Touron \& Hertzog, 2004a, 2004b, 2009, 2014; Touron, Swaim, \& Hertzog, 2007; cf. Hecht, 2006; Siegler, 1988, for demonstrations of individual differences in strategy choice among college students and children). Older adults' performance proceeds more slowly than young adults' (Touron, Hoyer, \& Cerella, 2001, 2004), which would be expected given the slowing of certain processes with age (e.g., Salthouse, 1996) and an associative learning deficit (Cerella, Onyper, \& Hoyer, 2006; Naveh-Benjamin, 2000; Onyper, Hoyer, \& Cerella, 2008). 
This work from Touron and colleagues has shown that in learning tasks such as the Noun-Pair Lookup Task, a dissociation can be made between older adults' retrieval use and their retrieval ability as indexed by memory tests, where extant theories of skill learning predict a one-to-one mapping between retrieval use and retrieval ability.

This dissociation can be tested in learning tasks where the algorithmic and retrieval strategies can be assessed separately. One such task is the Noun-Pair Lookup Task (Ackerman \& Woltz, 1994). In the Noun-Pair Lookup Task, participants verify whether a presented noun-noun pair is a match or mismatch with a pair in a lookup table presented above the cue. In consistently-mapped versions of the task, nouns in the lookup table are consistently paired together, so that the pairs can be learned. An optimal performer in this task would first need to scan the lookup table to confirm whether a pair is matched, and eventually transition to retrieving the pair to respond quickly and efficiently. Learning can be assessed by inserting recognition memory probes with the lookup table removed, requiring retrieval to correctly respond.

Older adults' performance on the Noun-Pair Lookup Task has consistently been found to be less efficient than young adults' performance (see Touron, 2015 for a review): most young adults learn the pairs quickly and shift to a retrieval strategy for each of the noun pairs, whereas older adults shift more slowly. Few older adults completely shift to retrieval and around $\sim 30 \%$ of the sample does not shift to retrieval at all (Rogers et al., 2000; Touron, 2015). Older adults' lower shift rates are not entirely mediated by an associative learning deficit, however. A number of confidence and strategy-related factors have been found to influence older adults' behavior in the Noun-Pair Lookup Task, including a conservative speed-accuracy tradeoff (Touron \& Hertzog, 2009; Touron et al., 2007; cf. Strayer \& Kramer, 1994), a tendency not to shift strategies until all of the noun pairs have been learned (Touron, 2006; Touron \& Hertzog, 2004a; 
Hines et al., 2011) despite having a strong feeling-of-knowing that they know the correct nounpair (Hertzog \& Touron, 2011), and a tendency to underestimate the efficiency of retrieving over scanning (Hertzog et al., 2007).

Older adults' avoidance of the retrieval strategy reflects an apprehensiveness toward the strategy itself rather than a lack of memorization. When trained on half of the noun pairs prior to the task, older adults avoid retrieval even for learned items (Touron \& Hertzog, 2004a); only when the complete set of items are trained to high levels of memory accuracy do they retrieve comparable to young adults (Hines et al., 2012). This suggests that older adults prefer using a consistent strategic set across all noun pairs rather than alternating strategies depending on how well they have learned specific noun pairs (Touron, 2006).

Older adults also show deficient monitoring of response latencies for retrieval relative to scanning (Hertzog et al., 2007), and show greater shifts to retrieval when given feedback on their RT latencies than when without feedback. When assessed on their mental models of the NounPair Lookup Task, it appears that older adults believe that retrieval use enhances RT at the expense of accuracy, which is not true late in practice when the pairs have been learned (Touron \& Hertzog, 2009; Touron et al., 2007). When recognition memory is assessed, older adults’ accuracy is considerably higher than their level of retrieval use, in line with the notion that they are deliberately choosing to scan rather than retrieve (Touron et al., 2007).

Older adults' suboptimal strategic behavior in the Noun-Pair Lookup Task is easily amenable to intervention, further supporting a metacognitive account of strategy use. When offered monetary incentives to retrieve in the Noun-Pair Lookup Task and in an alphabet arithmetic task, older adults exhibit similar retrieval rates to young adults (Touron et al., 2007; Touron \& Hertzog, 2009). Changing the utility of the scanning strategy by making the lookup 
table more difficult to scan and lowering the memory load also cause older adults to retrieve comparable to young adults (Touron \& Hertzog, 2004b). Inserting recognition memory probes also increases retrieval rates, whereby older adults experience success in using retrieval, demonstrating that they retrieve effectively (Rogers \& Gilbert, 1997; Rogers et al., 2000; Touron \& Hertzog, 2004a).

The present study sought to extend and corroborate this metacognitive explanation by varying the stimuli to be learned. To do so, we created an isomorph of the Noun-Pair Lookup Task, the Grocery-Price Lookup Task. We manipulated whether the pairs in the Grocery-Price Lookup Task had schematic support (Castel, 2005) by varying whether the pairings fit into familiar and well-established knowledge. Schematic support reflects an intrinsic and preexperimental relationship between associative pairs that participants can take advantage of to more easily encode the pairs into existing knowledge structures which provide retrieval cues at test (Castel, 2005; Craik \& Bosman, 1992). Age deficits are substantially reduced and sometimes completely alleviated when item-pairs have schematic support, which has been observed across a wide variety of domains, including grocery-item and price information (Amer, Giovanello, Grady, \& Hasher, 2018; Castel, 2005, 2007; Castel, McGillivray, \& Worden, 2013; Fine, Shing, \& Naveh-Benjamin, 2018; Flores, Hargis, McGillivray, Friedman, \& Castel, 2016; Mohanty, Naveh-Benjamin, \& Ratneshwar, 2016), semantically related word-pairs (e.g., Naveh-Benjamin, 2000; Naveh-Benjamin, Hussain, Guez, \& Bar-On, 2003), word-pairs presented in familiar grammatical structure (Smyth \& Naveh-Benjamin, 2018), and face-name pairs (e.g., Fine et al., 2018; Peterson et al., 2017; cf. Old \& Naveh-Benjamin, 2008).

Because intrinsic item features increase participants' confidence that they will learn and remember the information (Koriat, Ma'ayan, \& Nussinson, 2006), we expected that providing 
older adults schematic support in the Grocery-Price Lookup Task would increase their retrieval use and cause earlier shifts to retrieval than in a condition not providing schematic support. To test this hypothesis, we manipulated schematic support with two conditions where grocery-itemprice pairs were consistent with everyday prices or market-priced, or were overpriced.

We also tested whether older adults' retrieval reluctance is a general tendency or is sensitive to task characteristics. Large variability in older adults' retrieval use has been found in the Noun-Pair Lookup Task before, with some older adults retrieving never or rarely, some retrieving around the group aggregate level, and some similar to young adults (Rogers et al., 2000; Touron, 2015). To test this, we compared rates of retrieval use in the Noun-Pair Lookup Task and the Grocery-Price Lookup Task. Participants first completed the Noun-Pair Lookup Task and then completed the Grocery-Price Lookup Task. If retrieval reluctance is a consistent strategy used by a subset of older adults, we would expect strong correlations between retrieval use across tasks.

\section{Method}

Below we report how we determined our sample size, all data exclusions, all manipulations, and all measures in the study (Simmons, Nelson, \& Simonsohn, 2012).

\section{Participants}

Data were collected from 128 subjects, but only 120 were kept for analyses ${ }^{1}$, planning for 30 participants per cell. We planned our sample size using previous studies (e.g., Touron \&

\footnotetext{
${ }^{1}$ Eight subjects were excluded and replaced before conducting our analyses. Four subjects were excluded for program failure - three young adults and one older adult; two subjects for being outside normal age range of 18 to 35 for young adults (both over 45 years old); one young adult for noncompliance with instructions; and one older adult voluntarily withdrew from the study. Additional exclusions were necessary for specific tasks. Three participants were removed from all Noun-Pair Lookup Task analyses: one older adult's data were erased due to experimenter error, and two participants were removed for having accuracy statistically indistinguishable from
} 
Hertzog, 2014). A sensitivity power analysis indicated that with 30 participants per cell we had .8 power to detect an effect size of $d=0.74$ when comparing retrieval use between older adults in the two Grocery-Price Lookup Task conditions in the final block of practice. Young adults from the University of North Carolina at Greensboro subject pool were compensated with course credit. Community-dwelling older adults from the Adult Cognition Lab subject registry were compensated with $\$ 30$. Participants in this registry are pre-screened to exclude diagnoses or experiences that implicate cognitive impairment. Participants completed a demographics questionnaire, a vocabulary test, and a test of processing speed before starting the experimental tasks. Typical age differences were obtained and are shown in Table 1. Among these is a large age difference in education; the supplemental material includes a report of nonsignificant correlations between education and retrieval use to demonstrate that educational differences are not responsible for the critical findings in this paper. The experiment was approved by the University of North Carolina at Greensboro Institutional Review Board.

\section{Design}

The design includes age (young, old; between-subjects) and the independent variables Grocery-Price Lookup Task condition (market-priced, overpriced; between-subjects) and practice block ( $1-20$ for training, $1-2$ for recognition memory; within-subjects). The dependent variables include task accuracy, retrieval use, reaction time, recognition memory

chance by binomial test (adjusting alpha to .05/120; one young adult from the overpriced condition, and one older adult each from the market-priced and overpriced conditions). An additional two participants were removed from the recognition memory analyses for the NounPair Lookup Task due to noncompliance. Two participants were removed from all Grocery-Price Lookup Task analyses due to chance performance. Four participants were removed from PostTask Questionnaire analyses following the Noun-Pair Lookup Task due to lack of question comprehension. There were no significant differences in participant characteristics between excluded and included participants, $p \mathrm{~s}>.13$. 
performance, recall confidence, cued-recall accuracy, and post-task questionnaire items. Grocery-Price Lookup Task condition was included in the analysis of the Noun-Pair Lookup Task as a check on random assignment. Because all participants completed the same version of the Noun-Pair Lookup Task before completing the Grocery-Price Lookup Task, we would not expect condition differences.

\section{Materials}

Visual Basic 6.0 and E-Prime 2.0 were used to present the tasks and questionnaires to participants and to collect responses. Stimuli were presented in 14pt Arial font on a 15-in (38.1 cm) LCD monitor with a resolution of $1024 \times 768$. The stimulus set for the Noun-Pair Lookup Task contained 12 unrelated concrete noun pairs (e.g., ivy-bird, potato-frog). All 12 noun pairs were presented in the lookup table; the location for each pair changed within the table each trial, but the pairings were consistent. On each trial, a centrally presented target pair was matched to one of the pairs within the table for half of the presentations, and for the other half a mismatched target pair was presented (e.g., ivy-frog). Participants were asked to report whether the target pair was matched in the lookup table. Participants responded by pressing keys labeled "Y" for yes (match) or "N" for no (mismatch), and then a separate screen asked them to report the strategy they used to respond. Strategy report options included keys labeled "S" for scanning, " $\mathrm{M}$ " for retrieving the answer from memory, "B" for a combination of both scanning and memory, or "O" for other. The use of self-reported strategies has been previously validated using the NounPair Lookup Task with eye-tracking (Touron, Frank, \& Hertzog, 2010), where it was found that participants gazed at the lookup table when they reported scanning, but not when they reported retrieving. In the Supplemental Materials we report a validation of the self-reported strategies by comparing the response-time distributions for the scanning and retrieval strategies. 
The Grocery-Price Lookup Task is an isomorph of the Noun-Pair Lookup Task, differing only in the stimulus set: 12 grocery-items (accompanied by corresponding pictures to clarify the item names) and prices were presented in the lookup table (see Figure 1). Market-priced item prices were between $\$ 1$ and $\$ 2.99$, with all prices ending in 9 , where the prices were chosen from local grocery stores. Overpriced item prices were randomly generated between $\$ 12$ and $\$ 13.99$, again with all prices ending in 9 . We constrained the range of prices to prevent familiarity-based retrieval. This was particularly important for the market-priced condition where an implausibly re-paired item would be immediately obvious (e.g., Beans - \$4.99 could quickly be distinguished as unusual, whereas Beans - \$1.39 could be plausible, Mohanty \& Naveh-Benjamin, 2018).

\section{Procedure}

Participants were tested in groups from one to four on computers separated by cubicles, with the experimenter present. Participants in each session were assigned to the same condition, and condition was assigned randomly, with the constraint that approximately equal numbers of participants had been tested in each condition throughout the data collection period. Participants first gave informed consent and completed the measures in Table 1. Participants then completed the Noun-Pair Lookup Task, starting with practice trials and then 20 blocks of 24 trials each. Following training, participants received two blocks of recognition memory probes, where the matched and mismatched stimuli were presented without the lookup table; participants were not initially informed of these memory tests. Each block in the task was followed with a mandatory ten-second break and the option to take a longer break if necessary, to prevent fatigue.

Following the Noun-Pair Lookup Task, participants completed a survey regarding their task performance, including overall task confidence, estimated number of pairs learned, global confidence in memory-use, item-level cued judgments of learning (i.e., asking for confidence, 0- 
100, that they will remember the second item when shown the first item in the pair), and cuedrecall for the second item in the pair (e.g., ivy-___ $)$.

Participants next completed the Grocery-Price Lookup Task in either the market-priced or overpriced condition. The task was functionally identical to the Noun-Pair Lookup Task. The Grocery-Price Lookup Task was also followed by a survey, including the same questions asked previously for the Noun-Pair Lookup Task as well as questions about overall self-evaluated study performance and confidence, ratings of task difficulty, difficulty of the Noun-Pair Lookup Task compared to the Grocery-Price Lookup Task, familiarity with the grocery items in the task, and how often they grocery shop. The specific questions can be found in the Supplemental Materials. $^{2}$

\section{Results}

For all analyses, $\alpha$ was set at .05. ANOVAs were run using the afex package, with Greenhouse-Geisser corrections where appropriate (Singmann, Bolker, Westfall, \& Aust, 2017), and post-hoc tests were run with the emmeans package (Lenth, 2019) in the $R$ statistical programming language (R Core Team, 2017). We report generalized eta squared as a measure of effect size in our ANOVAs because it allows for accurate comparisons of an effect across studies, even when the underlying designs vary (Bakeman, 2005; Olejnik \& Algina, 2003). We also report effect sizes for Tukey's HSD tests as Cohen's d.

We performed separate 2 (age: young, old) by 2 (condition: market-priced, overpriced) by Block (20 for task practice; 2 for recognition memory) repeated measures ANOVAs to

\footnotetext{
${ }^{2}$ Finally, participants completed a questionnaire about memory beliefs, the General and Personal Beliefs about Memory Instrument (GBMI and PBMI, Lineweaver \& Hertzog, 1998; Hertzog et al., 2014). Analyses of PBMI data are reported in the Supplemental Materials, and data from the GBMI are not reported here because they were not theoretically relevant.
} 
analyze task accuracy, reaction times, retrieval use, and recognition memory performance in both the Noun-Pair Lookup Task and Grocery-Price Lookup Task. We also performed 2 (age: young, old) by 2 (condition: market-priced, overpriced) ANOVAs for retrieval use in the final block of practice, and confidence in using the memory strategy. We performed 2 (age: young, old) by 2 (condition: market-priced, overpriced) by 2 (memory type: retrieval use, recognition memory test performance) ANOVAs to determine age and condition differences in how retrieval use tracked actual learning. ANOVA tables are presented in Table 2 for the Noun-Pair Lookup Task and in Table 3 for the Grocery-Price Lookup Task.

\section{Noun-Pair Lookup Task}

Task accuracy. Older adults were more accurate than young adults $(M=.93, S E=.01$; $M=.97, S E=.01$, for young and older adults, respectively). No other effects were significant. This pattern is typical for accuracy in this task (e.g., Touron \& Hertzog, 2004a, 2004b; Touron et al., 2007).

Retrieval use. Young adults used retrieval more often than older adults (see Figure 2), and retrieval use increased over blocks. Young adults also increased their retrieval use at a faster rate than older adults, corroborated by an age by block interaction. No other effects were significant.

We also directly compared retrieval use in the last block of practice. Young adults retrieved more than older adults, and we obtained a small effect of condition. This was unexpected as there was no manipulation of condition for the Noun-Pair Lookup Task, which was completed before the Grocery-Price Lookup Task. The interaction between age and condition was not significant. 
Inspection of Figure 2 shows that participants in the market-priced condition retrieved at higher rates than those in the overpriced condition across most of the task. These results may indicate that participants in the overpriced condition, by chance, had a lesser tendency to transition to retrieval strategies. Exploratory pairwise comparisons of retrieval use between the two conditions within each age group were conducted for each block to investigate this difference. We set alpha to .05/20 to correct for multiple comparisons. No significant differences emerged for young adults, $p \mathrm{~s}>.06, d_{\max }=0.48$, or older adults, $p \mathrm{~s}>.09, d_{\max }=.45$.

Reaction times. Young adults were faster than older adults throughout the task (see the left panels of Figure 3). Reaction times sped up with practice, for a main effect of block. The age by block interaction was significant, indicating that young adults improved at a faster rate than older adults. There were no other significant effects or interactions.

Recognition memory. Recognition memory for the Noun-Pair Lookup Task (proportion correct in the first block) is shown on the right axis of Figure 2. We calculated $d$ ' for recognition memory (z(hits) - $\mathrm{z}$ (false alarms)), comparing scores across the two blocks of recognition memory tests to determine whether learning is stable or improves over these blocks. Hit and false alarm rates were corrected for performance at ceiling and floor, such that either $1-1 /(2 \mathrm{~N})$ or $1 /(2 N)$ was used for ceiling and floor rates, respectively (Macmillan \& Creelman, 2005). Young adults had higher sensitivity than older adults (Young adults: $M(S E)=3.14(.09)$, OAs: $M(S E)$ $=2.11(.15))$, but there were no other significant effects. The same pattern was obtained for raw recognition memory performance. Age differences in recognition memory have been found routinely in this task (Touron \& Hertzog, 2004b, 2009; Touron et al., 2007). Improvements in memory performance across test blocks has also been observed in some studies, contrary to the stability found here (Touron \& Hertzog, 2009; Touron et al., 2007). 
Retrieval use compared to recognition memory performance. We examined age and condition differences across memory type, comparing the last block of retrieval and the first block of recognition memory tests, to consider how retrieval use tracked actual learning. Young adults showed better overall memory compared to older adults, and we also found a small and unexpected effect of condition. We found a main effect of memory type, with lower retrieval use compared to recognition memory accuracy. The interaction of age and memory test was significant, consistent with previous findings that older but not young adults are retrieval reluctant, with retrieval strategy use lower than their level of learning. No other effects were significant.

Post-hoc Tukey HSD tests showed that while there were significant differences between retrieval use and proportion correct for the older adults, $p \mathrm{~s}<.0001, d \mathrm{~s}>2.24$, there were no differences between retrieval use and recognition memory performance for the young adults, $p \mathrm{~s}$ $>.32, d \mathrm{~s}<.59$. Within each age group, there were no differences between condition for either retrieval use, $p \mathrm{~s}>.21, d \mathrm{~s}<.98$, or recognition memory performance, $p \mathrm{~s}>.99, d \mathrm{~s}<.25$.

\section{Grocery-Price Lookup Task}

Task accuracy. Older adults were more accurate than young adults $(M=.91, S E=.003$; $M=.96, S E=.002$, for young and older adults, respectively). This was qualified by an age by condition interaction. There was also a main effect of block, qualified by a three-way interaction of age by condition by block. Younger adults in the overpriced condition became less accurate over time, from $M=.94, S E=.01$ in the first block, to $M=0.86, S E=0.03$ in the final block of practice, a difference of .08 , where all other groups experienced changes $\leq .03$ in proportion accuracy. These differences in accuracy levels, while unexpected, don't change the interpretation of the results. Overall, accuracy was high across conditions and blocks. 
Retrieval use. Retrieval use increased with practice (see Figure 4). Young adults retrieved more than older adults, participants in the market-priced condition retrieved more than those in the overpriced condition, and participants in the market-priced condition shifted to retrieval faster than those in the overpriced condition. These results were confirmed with main effects of age, condition, block, and a condition by block interaction. No other effects were significant. A similar pattern of effects was found in the final block of practice, where older adults retrieved less than young adults, and participants in the market-priced condition retrieved more than those in the overpriced condition. The lack of an age by condition interaction suggests no support for the hypothesis that age differences in retrieval use are reduced by schematic support.

It is possible that random assignment did not result in equivalent groups. As noted above, there were condition differences in the final block of retrieval use in the Noun-Pair Lookup Task. We therefore included retrieval use from that task, centered by condition, as a covariate in the analyses of retrieval use in the Grocery-Price Lookup Task across blocks and in the final block of practice (see Table 3). In both analyses, the critical pattern of effects was unchanged. As expected, the main effect of age was no longer significant because this variance is present in the covariate. The effects of Grocery-Price Lookup Task condition were still significant, indicating that any sampling differences in the general tendency to use retrieval do not account for the results.

The pattern of retrieval use was not exactly as predicted. Our prediction that older adults in the market-priced condition would retrieve more than older adults in the overpriced condition was confirmed. Unexpectedly, young adults also showed differences in retrieval use depending on condition, where those in the market-priced condition retrieved more than those in the 
overpriced condition. Young adults have not shown condition differences in retrieval use in other studies using the Noun-Pair Lookup Task (e.g., Touron \& Hertzog, 2004b; Touron et al., 2007; cf. Touron \& Hertzog, 2004b), although prior studies have not manipulated the kind of memoranda as was done in the present experiment. These results suggest that schematic support can alter retrieval use to a similar extent in both young and older adults.

Reaction times. Reaction times sped up with increasing practice. Main effects of age, condition, and block were found. These effects were qualified by age by block and condition by block interactions. These data are shown in the right panels of Figure 3. Unsurprisingly, young adults were faster than older adults, and decreased their reaction times at a faster rate. Participants in market-priced condition were faster than those in the overpriced condition and decreased their reaction times at a faster rate. This pattern is primarily due to differences in strategy use - retrieving is faster than scanning. Validation of this assumption is reported in the Supplemental Materials.

Recognition memory. Proportion correct memory accuracy is shown on the right panel of Figure 4. We calculated $d$ ' to compare recognition memory between groups. Hit and false alarm rates were corrected when at ceiling or floor in the same manner as with the Noun-Pair Lookup Task (Macmillan \& Creelman, 2005). A repeated measures ANOVA revealed a significant effect of condition, where participants in the market-priced condition had significantly higher sensitivity than those in the overpriced condition, (Market-priced condition $M(S E)=2.95(.05)$; Overpriced condition $M(S E)=1.90(.09))$. No other effects were significant. Post-hoc tests showed that the condition effect was significant in both age groups, $p \mathrm{~s}$ $<.001, d_{\min }=1.87$. 
The lack of difference between the young and older adults in the market-priced condition should be interpreted cautiously though, as there appear to be ceiling effects. For both age groups in this condition, close to half of the participants had perfect accuracy (12/29 young adults; 11/30 older adults), and more than $2 / 3$ of the participants had proportion accuracy greater than .9 (25/29 young adults; $23 / 30$ older adults). While the ceiling effects prevent comparison of the two age groups in the market-priced condition, comparison between the market and overpriced conditions still holds.

Retrieval use compared to recognition memory performance. We again examined age and condition differences across memory type, comparing the last block of retrieval and the first block of recognition memory tests, to consider how retrieval use tracked actual learning. Young adults showed better overall memory compared to older adults, and participants in the marketpriced condition showed better overall memory compared to those in the over-priced condition. We again found a main effect of memory type, with lower retrieval use compared to recognition memory ability. Memory type interacted with both age and condition. No other effects were significant.

Post-hoc Tukey HSD tests showed that each age by condition group, except for young adults in the market-priced condition, had lower retrieval use compared to their recognition memory performance, $p \mathrm{~s}<.004, d \mathrm{~s}>1.02$. Additionally, age comparisons within each condition showed that retrieval use in the market-priced condition did not differ between young and older adults, $p=.72, d=.52$, but retrieval use in the overpriced condition did differ between young and older adults, $p=.004, d=1.21$. Recognition memory performance was equivalent for young and older adults within each condition, $p \mathrm{~s}>.99, d \mathrm{~s}<.27$. These results indicate that the young adults in the overpriced condition were also retrieval avoidant, but not to the same extent as older 
adults in the overpriced condition. Older adults in the market-priced condition were retrieval avoidant as well, despite increased retrieval use.

Retrieval Use between tasks. We correlated retrieval use in the final block of the NounPair and Grocery-Price Lookup Tasks, to detect if patterns of retrieval use were stable across the two tasks, collapsing across age group and condition to increase power. We report the results of including and excluding participants that never endorsed retrieving (which we call "nonretrievers"), because they dramatically change the pattern of results. The suite of correlations is reported in Table 4 and the scatterplots are displayed in the Supplemental Materials. Young adults' retrieval use seems to be determined by the task for the most part - the correlation including non-retrievers was significant due to two participants who never endorsed retrieval in either task. Older adults' retrieval use in the Noun-Pair Lookup Task was predictive of retrieval use in the Grocery-Price Lookup Task, suggesting that use of the retrieval strategy may be a stable individual difference for older adults.

\section{Post-Task Questionnaires}

Means and standard errors from the measures of interest from the post-task questionnaires are reported in Table 5. Results for both the Noun-Pair and Grocery-Price Lookup Tasks mostly were consistent with previous analyses, with age differences in the Noun-Pair Lookup Task and condition differences in the Grocery-Price Lookup Task. Full reporting of these analyses can be found in the Supplemental Materials. We were particularly interested in global confidence in using the memory strategy in each task.

In the Noun-Pair Lookup Task, the pattern of results replicated previous findings (Touron \& Hertzog, 2004a, 2004b; Touron et al, 2007), where older adults felt less confident in using the 
memory strategy than young adults (see Table 2). The condition effect and the age by condition interaction did not reach significance.

In the Grocery-Price Lookup Task, participants in the market-priced condition felt more confident in using the memory strategy than participants in the overpriced condition (see Table 3). No other effects were significant. This result is striking, especially in reference to young and older adults' retrieval use in the overpriced condition. While young and older adults' retrieval use in the overpriced condition diverged at the end of practice, their confidence in their retrieval use did not. This suggests confidence in retrieval use contributed similarly to each age groups' sub-optimal retrieval use.

We conducted a series of Pearson correlations to examine the relationship between posttask rated measures of confidence and memory measures with end retrieval use between young and older adults, aggregating over condition. These correlations are reported in Table 6 . These findings are noteworthy for several reasons. The pattern of older adults' correlations in the Noun-Pair Lookup Task replicates prior work (Frank et al., 2013; Touron \& Hertzog, 2004a, 2009; Touron et al., 2007), where older adults' retrieval use is correlated with indices of task confidence. Contrasting with previous work was the young adults' significant pattern of correlations in the Grocery-Price Lookup Task, which suggests young adults' confidence in the retrieval strategy will vary between tasks involving a shift to retrieval, depending on the type of task materials. Further work is needed to explore the generality of this claim.

\section{Discussion}

The present study revealed that young and older adults' retrieval strategy use is tied to their confidence in the task materials. Schematic support was varied in the Grocery-Price Lookup Task, extending studies of retrieval strategies in the Noun-Pair Lookup Task. Older adults were 
retrieval reluctant in the overpriced condition that lacked schematic support, but much less so in the market-priced condition which had schematic support. Surprisingly, young adults showed analogous retrieval reluctance in the overpriced condition - their use of the memory strategy was less than would be expected given their memory performance.

This study demonstrates that older adults are not uniformly reluctant to adopt memorybased strategies across all situations (Touron, 2015). Older adults' confidence in using a memory-based strategy appears to be critical to whether it is used, with memory strategy use varying depending on the material to be learned. Older adults tend to show small to no differences compared to young adults on associative memory measures when the pairs are related (Old \& Naveh-Benjamin, 2008), in part due to the ease with which one can incorporate the pairs into existing schematic frameworks. We contend that this ease translated into older adults' increased confidence and success in using their memory in the market-priced condition of the Grocery-Price Lookup Task.

Surprisingly, young adults in the overpriced condition of the Grocery-Price Lookup Task showed far less retrieval use than would be expected from previous work (Hertzog et al., 2007; Touron et al., 2001, 2004; Touron \& Hertzog, 2004a, 2004b, 2009; Touron et al., 2007). In these previous studies, young adults have made quick and consistent shifts to retrieval across various tasks and manipulations. The difference in the present experiment is that we manipulated the kind of material being learned between conditions rather than varying structural aspects of the task (Hertzog et al., 2007; Touron et al., 2001, 2004, Touron \& Hertzog, 2004a, 2004b; Touron et al., 2007). Note, however, that condition differences in retrieval use have been obtained with a novel arithmetic task, where a young adult group offered incentives retrieved slightly more quickly when compared with a group of young adults given standard instructions (Touron \& 
Hertzog, 2009). Furthermore, because small to negligible differences in young adults' memory for market- and overpriced grocery-price pairs have been previously observed (Amer et al., 2018; Castel, 2005, 2007; Castel et al., 2014; Flores et al., 2016), we expected that any early condition differences between the young adult conditions in the Grocery-Price Lookup Task would diminish over the course of practice.

These results add to a burgeoning literature on schematic support. Counter to previous findings using grocery-price pairs (Amer et al., 2018; Castel, 2005, 2007; Castel et al., 2014; Fine et al., 2018; Flores et al., 2016), we found large and reliable effects of schematic support in both young and older adults. This effect may be a function of our task's reliance on recognition memory - the cued-recall tasks used in previous work (Castel, 2005, 2007; Castel et al., 2014; Flores et al., 2016) rely on different although not mutually exclusive mnemonic processes at retrieval which may interact differently with schematic support. Indeed, when investigating schematic support via associative recognition tasks, young adults can show better memory for schema-typical over schema-atypical pairs (Amer et al., 2018; Delhaye, Folville, \& Bastin, 2019; Fine et al., 2018; Mohanty et al., 2016; Patterson, Light, Van Ocker, \& Olfman, 2009; Smyth \& Naveh-Benjamin, 2018), but these results are inconsistently found (e.g., Peterson et al., 2017). The present findings suggest one important avenue for understanding the effects of schematic support on young and older adults' memory is the confidence that they have in learning and relying on their memory.

The current results are also valuable because they establish that young adults' confidence in retrieval use can be an important factor in learning tasks that afford a shift to retrieval. In particular, they corroborate the retrieval reluctance account of older adults' strategic behavior by showing that retrieval reluctance is not merely an age-related phenomenon. The current results 
suggest that previous materials used to study this area were perhaps too easy for young adults, reminiscent of Touron and Hertzog's (2004b) notion of strategy shift affordance, and that subjective perceptions of the cost-benefit ratio for the retrieval strategy are influenced by experimental manipulations. Without proper consideration of task and strategy shift affordances, variability in young adults' performance may be substantially reduced, covering up any potential to find differences in young adults' strategic behavior, which can lead to flawed conclusions about the nature of age-related cognitive change (Hertzog, 2008). Careful consideration of this issue remains an important goal for future research.

A surprising finding was the modest correlation in the final blocks between retrieval use in the Grocery-Price and Noun-Pair Lookup Tasks when excluding non-retrievers $(r=.29)$. When including non-retrievers, a much stronger relationship was obtained $(r=.51)$. The two correlations capture at least two distinct groups: those that retrieve, and those that don't. In the first sense, the correlation may be interpreted as showing a modest positive relationship between the two tasks for those that do retrieve. In the latter sense, the correlation seems to capture a traitlike profile, whereby not endorsing retrieval seems to be determined by the person, not the task. Non-retrievers, both young and old, are consistently found in learning and memory search tasks (e.g., Ackerman \& Woltz, 1994; Frank et al., 2013; Rickard, 1997; Rogers et al., 2000; Schunn et al., 1997; Touron, 2015). What the present work shows is that the non-retrievers of one task are not necessarily the non-retrievers of another task, and that researchers should consider intraindividual differences in strategy use as well as interindividual differences.

Our interpretation of retrieval reluctance is limited by ceiling effects in the recognition memory task for the market-priced condition of the Grocery-Price Lookup Task. Our analysis suggests that some older adults in the market-priced condition were retrieval reluctant, but our 
results are inconclusive. The results from the overpriced condition suggest that both the young and older adults were retrieval reluctant. Interpretation of the pattern of results in the present experiment suggests that ceiling effects may have limited the ability to find differences in young adult groups in prior work. Further, task accuracy in the Noun-Pair and Grocery-Price Lookup Tasks was near ceiling. Accuracy can vary considerably in skilled performance, especially if one is training through deliberate practice (e.g., Ericsson, Krampe \& Tesch-Römer, 1993). It is unknown how tasks that do not afford high levels of accuracy affect shifts to retrieval or retrieval reluctance, although some mathematical models of shift-to-retrieval learning explicitly specify that task difficulty does not directly influence the shift to retrieval, except in cases with differing algorithm difficulty — which was not the case in the Grocery-Price Lookup Task (e.g., Logan, 1988; Rickard, 1997; see Touron \& Hertzog, 2004b for a demonstration of this phenomenon in the Noun-Pair Lookup Task).

This study demonstrated that strategic choice in a learning task that affords a shift from algorithmic processing to memory-based processing can be influenced by schematic support, for both young and older adults. These findings also suggest that confidence in memory strategy use is an important factor in determining both young and older adults' memory strategy use, depending on whether schematic support is provided. Investigating how task materials affect young and older adults' confidence in memory-based responding will enable a better understanding of the factors that underlie the shift to retrieval. 


\section{References}

Ackerman, P. L., \& Woltz, D. J. (1994). Determinants of Learning and Performance in an Associative Memory Substitution Task - Task Constraints, Individual-Differences, Volition, and Motivation. Journal of Educational Psychology, 86(4), 487-515. https://doi.org/10.1037/0022-0663.86.4.487

Amer, T., Giovanello, K. S., Grady, C. L., \& Hasher, L. (2018). Age differences in memory for meaningful and arbitrary associations: A memory retrieval account. Psychology and Aging, 33(1), 74-81. https://doi.org/10.1037/pag0000220

Anderson, J. R. (1982). Acquisition of cognitive skill. Psychological review, 89(4), 369-406.

Bajic, D., \& Rickard, T. C. (2009). The temporal dynamics of strategy execution in cognitive skill learning. Journal of Experimental Psychology: Learning, Memory, and Cognition, 35(1), 113-121. https://doi.org/10.1037/a0013647

Bajic, D., \& Rickard, T. C. (2011). Toward a generalized theory of the shift to retrieval in cognitive skill learning. Memory \& Cognition, 39(7), 1147-1161. https://doi.org/10.3758/s13421-011-0114-z

Bakeman, R. (2005). Recommend effect size statistics for repeated measure designs. Behavior Research Methods, 37(3), 379-384.

Beaudoin, M., \& Desrichard, O. (2011). Are memory self-efficacy and memory performance related? A meta-analysis. Psychological Bulletin, 137(2), 211-241. https://doi.org/10.1037/a0022106

Bryan, W. L., \& Harter, N. (1897). Studies in the physiology and psychology of the telegraphic language. Psychological Review, 4(1), 27-53.

Castel, A. D. (2005). Memory for grocery prices in younger and older adults: the role of 
schematic support. Psychology and Aging, 20(4), 718-721. https://doi.org/10.1037/08827974.20.4.718

Castel, A. D. (2007). Aging and memory for numerical information: The role of specificity and expertise in associative memory. The Journals of Gerontology. Series B, Psychological Sciences and Social Sciences, 62(3), 194-196. https://doi.org/10.1093/geronb/62.3.P194

Castel, A. D., McGillivray, S., \& Worden, K. M. (2013). Back to the future: Past and future erabased schematic support and associative memory for prices in younger and older adults. Psychology \& Aging, 28(4), 996-1003.

Cerella, J., Onyper, S. V., \& Hoyer, W. J. (2006). The associative-memory basis of cognitive skill learning: Adult age differences. Psychology and Aging, 21(3), 483-498. https://doi.org/10.1037/0882-7974.21.3.483

Craik, F. I. M., \& Bosman, E. A. (1992). Age-related changes in memory and learning. In H. Bouma \& J. A. M. Graafmans (Eds.), Gerontechnology (79-92). Amsterdam: IOS Press.

Delaney, P. F., Reder, L. M., Staszewski, J. J., \& Ritter, F. E. (1998). The Strategy-Specific Nature of Improvement: The Power Law Applies by Strategy Within Task. Psychological Science, 9(1), 1-7. https://doi.org/10.1111/1467-9280.00001

Delhaye, E., Folville, A., \& Bastin, C. (2019). How to induce an age-related benefit of semantic relatedness in associative memory: It's all in the design. Psychology and Aging, 34(4), 572-586. http://dx.doi.org/10.1037/pag0000360

Ericsson, K. A., Krampe, R. T., \& Tesch-Römer, C. (1993). The role of deliberate practice in the acquisition of expert performance. Psychological Review, 100(3), 363.

Fine, H. C., Shing, Y. L., \& Naveh-Benjamin, M. (2018). Effects of changes in schematic support and of item repetition on age-related associative memory deficits: Theoretically- 
driven empirical attempts to reduce older adults' high false alarm rate. Psychology and Aging, 33(1), 57-73. https://doi.org/10.1037/pag0000211

Frank, D. J., Touron, D. R., \& Hertzog, C. (2013). Age differences in strategy shift: Retrieval avoidance or general shift reluctance? Psychology and Aging, 28(3), 778-788. https://doi.org/10.1037/a0030473

Flores, C. C., Hargis, M. B., McGillivray, S., Friedman, M. C., \& Castel, A. D. (2016). Gistbased memory for prices and "better buys" in younger and older adults. Memory, 25(4), 565-573. https://doi.org/10.1080/09658211.2016.1197944

Hecht, S. A. (2006). Group differences in adult simple arithmetic: Good retrievers, not-so-good retrievers, and perfectionists. Memory and Cognition, 34(1), 207-216. https://doi.org/10.3758/BF03193399

Hertzog, C. (2008). Theoretical approaches to the study of cognitive aging: An individualdifferences perspective. In S. M. Hofer \& D. F. Alwin (Eds.), Handbook of cognitive aging: Interdisciplinary perspectives. (pp. 34-49). Thousand Oaks, CA: Sage Publications, Inc.

Hertzog, C., Lineweaver, T. T., \& Hines, J. C. (2014). Computerized assessment of age differences in memory beliefs. Perceptual and Motor Skills, 119(2), 609-628. https://doi.org/10.2466/03.10.PMS.119c23z4

Hertzog, C., \& Touron, D. R. (2011). Age differences in memory retrieval shift: Governed by feeling-of-knowing? Psychology and Aging, 26(3), 647-660. https://doi.org/10.1037/a0021875

Hertzog, C., Touron, D. R., \& Hines, J. C. (2007). Does a time-monitoring deficit influence older adults' delayed retrieval shift during skill acquisition? Psychology and Aging, 22(3), 
607-624. https://doi.org/10.1037/0882-7974.22.3.607

Hines, J. C., Hertzog, C., \& Touron, D. R. (2011). A prelearning manipulation falsifies a pure associational deficit account of retrieval shift during skill acquisition. Neuropsychology, Development, and Cognition. Section B, Aging, Neuropsychology and Cognition, 19(4), 449-478. https://doi.org/10.1080/13825585.2011.630718

Koriat, A., Ma'ayan, H., \& Nussinson, R. (2006). The intricate relationships between monitoring and control in metacognition: Lessons for the cause-and-effect relation between subjective experience and behavior. Journal of Experimental Psychology: General, 135(1), 36-69. https://doi.org/10.1037/0096-3445.135.1.36

Lamson, N., \& Rogers, W. A. (2008). Assessing age-related patterns in strategy selection on a mathematical problem-solving task. Journals of Gerontology - Series B Psychological Sciences and Social Sciences, 63(3), 146-155. https://doi.org/10.1093/geronb/63.3.P146

Lenth, R. (2019). emmeans: Estimated Marginal Means, aka Least-Squares Means. R package version 1.4. https://CRAN.R-project.org/package=emmeans

Lineweaver, T. T., \& Hertzog, C. (1998). Adults' efficacy and control beliefs regarding memory and aging: Separating general from personal beliefs. Aging, Neuropsychology, and Cognition, 5, 264-296. https://doi.org/10.1076/anec.5.4.264.771

Logan, G. D. (1988). Toward an instance theory of automatization. Psychological Review, 95(4), $492-527$.

Macmillan, N. A., \& Creelman, C. D. (2005). Signal Detection theory: A user's guide (2nd ed.). Mahwah, NJ: Erlbaum.

Miller, J. (1982). Divided attention: Evidence for coactivation with redundant signals. Cognitive Psychology, 14, 247-279. 
Mohanty, P., \& Naveh-Benjamin, M. (2018). Mitigating the adverse effects of response deadline on recognition memory: Differential effects of semantic memory support on item and associative memory. Journal of Memory and Language, 102, 182-194. https://doi.org/10.1016/j.jml.2018.05.010

Mohanty, P. P., Naveh-Benjamin, M., \& Ratneshwar, S. (2016). Beneficial effects of semantic memory support on older adults' episodic memory: Differential patterns of support of item and associative information. Psychology and Aging, 31(1), 25-36. https://doi.org/10.1037/pag0000059

Naveh-Benjamin, M. (2000). Adult age differences in memory performance: Tests of an associative deficit hypothesis. Journal of Experimental Psychology: Learning, Memory, and Cognition, 26(5), 1170-1187. https://doi.org/10.1037//0278-7393.26.5.1170

Nino, R. S., \& Rickard, T. C. (2003). Practice effects on two memory retrievals from a single cue. Journal of Experimental Psychology: Learning, Memory, and Cognition, 29(3), 373-388. https://doi.org/10.1037/0278-7393.29.3.373

Old, S. R., \& Naveh-Benjamin, M. (2008). Differential effects of age on item and associative measures of memory: a meta-analysis. Psychology and Aging, 23(1), 104-118. https://doi.org/10.1037/0882-7974.23.1.104

Olejnik, S., \& Algina, J. (2003). Generalized eta and omega squared statistics: Measures of effect size for some common research designs. Psychological Methods, 8(4), 434-447.

Patterson, M. M., Light, L. L., Van Ocker, J. C., \& Olfman, D. (2009). Discriminating semantic from episodic relatedness in young and older adults. Aging, Neuropsychology, and Cognition, 16(5), 535-562.

Peterson, D. J., Schmidt, N. E., \& Naveh-Benjamin, M. (2017). The role of schematic support in 
age-related associative deficits in short-term and long-term memory. Journal of Memory and Language, 92, 79-97. https://doi.org/10.1016/j.jml.2016.05.007

R Core Team (2017). R: A language and environment for statistical computing. R Foundation for Statistical Computing, Vienna, Austria. Available from https://www.R-project.org/.

Ratcliff, R. (1979). Group reaction time distributions and an analysis of distribution statistics. Psychological bulletin, 86(3), 446.

Rawson, K. A., \& Touron, D. R. (2009). Age differences and similarities in the shift from computation to retrieval during reading comprehension. Psychology and Aging, 3, 423437.

Rawson, K. A., \& Touron, D. R. (2015). Preservation of memory-based automaticity in reading for older adults. Psychology and Aging, 4(30), 809-823.

Rickard, T. C. (1997). Bending the power law: A CMPL theory of strategy shifts and the automatization of cognitive skills. Journal of Experimental Psychology: General, 126(3), $288-311$.

Rickard, T. C. (1999). A CMPL alternative account of practice effects in numerosity judgment tasks. Journal of Experimental Psychology: Learning, Memory, and Cognition, 25(2), 532-542. https://doi.org/10.1037/0278-7393.25.2.532

Rogers, W. A., \& Gilbert, D. K. (1997). Do performance strategies mediate age-related differences in associative learning? Psychology and Aging, 12(4), 620-633. https://doi.org/10.1037/0882-7974.12.4.620

Rogers, W. A., Hertzog, C., \& Fisk, A. D. (2000). An individual differences analysis of ability and strategy influences: Age-related differences in associative learning. Journal of experimental psychology: Learning, Memory, and Cognition, 26(2), 359-394. 
https://doi.org/10.1037/0278-7393.26.2.359

Siegler, R. S. (1988). Individual Differences in Strategy Choices : Good Students, Not-So-Good Students, and Perfectionists. Child Development, 59(4), 833-851.

Simmons, J. P., Nelson, L. D., \& Simonsohn, U. (2012). A 21 Word Solution. Dialogue: The Official Newsletter of the Society for Personality and Social Psychology, 26(2), 4-12.

Singmann, H., Bolker, B., Westfall, J., \& Aust, F. (2017). afex: Analysis of Factorial Experiments. R package version 0.18-0. https://cran.r-project.org/package=afex

Smyth, A. C., \& Naveh-Benjamin, M. (2018). Existing knowledge of linguistic structure mitigates associative memory deficits in older adults. Experimental Aging Research, 44(1), 35-47. https://doi.org/10.1080/0361073X.2017.1398517

Strayer, D. L., \& Kramer, A. F. (1994). Aging and skill acquisition: Learning-performance distinctions. Psychology and Aging, 9(4), 589-605. https://doi.org/10.1037/08827974.9.4.589

Touron, D. R. (2006). Are item-level strategy shifts abrupt and collective? Age differences in cognitive skill acquisition. Psychonomic Bulletin \& Review, 13(5), 781-786. https://doi.org/10.3758/BF03193997

Touron, D. R. (2015). Memory avoidance by older adults: When “old dogs" won't perform their “new tricks.” Current Directions in Psychological Science, 24(3), 170-176. https://doi.org/10.1177/0963721414563730

Touron, D. R., \& Hertzog, C. (2004a). Distinguishing Age Differences in Knowledge, Strategy Use, and Confidence During Strategic Skill Acquisition. Psychology and Aging, 19(3), 452-466. https://doi.org/10.1037/0882-7974.19.3.452

Touron, D. R., \& Hertzog, C. (2004b). Strategy shift affordance and strategy choice in young and 
older adults. Memory \& Cognition, 32(2), 298-310. https://doi.org/10.3758/BF03196860

Touron, D. R., \& Hertzog, C. (2009). Age differences in strategic behavior during a computation-based skill acquisition task. Psychology and Aging, 24(3), 574-585. https://doi.org/10.1037/a0015966

Touron, D. R., Hoyer, W. J., \& Cerella, J. (2001). Cognitive skill acquisition and transfer in younger and older adults. Psychology and Aging, 16(4), 555-563. https://doi.org/10.1037//0882-7974.16.4.555

Touron, D. R., Hoyer, W. J., \& Cerella, J. (2004). Cognitive skill learning: age-related differences in strategy shifts and speed of component operations. Psychology and Aging, 19(4), 565-580. https://doi.org/10.1037/0882-7974.19.4.565

Touron, D. R., Swaim, E. T., \& Hertzog, C. (2007). Moderation of older adults' retrieval reluctance through task instructions and monetary incentives. Journal of Gerontology: Psychological Sciences, 62B(3), 149-155. https://doi.org/10.1093/geronb/62.3.P149

Townsend, J. T. (1990). Truth and consequences of ordinal differences in statistical distributions: Toward a theory of hierarchical inference. Psychological Bulletin, 108(3), 551-567. https://doi.org/10.1037/0033-2909.108.3.551

Van Zandt, T. (2000). How to fit a response time distribution. Psychonomic Bulletin \& Review, $7(3), 424-465$.

Wechsler, D. (1981). Wechsler Adult Intelligence Scale - Revised. New York: Psychological Corporation.

Zachary, R. A., \& Shipley, W. C. (1986). Shipley institute of living scale: Revised manual. WPS, Western Psychological Services. 
Table 1

Demographic information

\begin{tabular}{lcccc}
\hline & \multicolumn{2}{c}{ Young } & \multicolumn{2}{c}{ Old } \\
\cline { 2 - 5 } \multicolumn{1}{c}{ Measure } & MP & OP & MP & OP \\
\hline Age (years) & $19.33(0.32)$ & $19.53(0.31)$ & $67.89(0.76)$ & $68.17(0.76)$ \\
Education & $12.80(0.18)$ & $12.86(0.22)$ & $16.24(0.44)$ & $16.20(0.42)$ \\
No. medications & $0.56(0.18)$ & $0.97(0.21)$ & $1.97(0.33)$ & $2.23(0.26)$ \\
Vocabulary & $27.33(0.66)$ & $27.87(0.87)$ & $34.57(0.79)$ & $34.33(0.62)$ \\
Digit-Symbol & $61.50(1.61)$ & $57.47(2.15)$ & $49.90(1.80)$ & $49.63(1.72)$ \\
Digit Symbol memory & $7.93(0.21)$ & $6.76(0.39)$ & $5.00(0.39)$ & $4.70(0.37)$ \\
\hline
\end{tabular}

Note. Demographic information reflects final sample, except for one older adults' data lost to

experimenter error $(\mathrm{N}=119)$. All age-group comparisons were significant. Means and standard errors in parentheses are displayed. Vocabulary was measured using the Shipley test (Zachary \& Shipley, 1996). Processing speed was measured using the WAIS-R Digit Symbol subtest (Wechsler, 1981). For Digit Symbol memory, there was a significant condition effect, seemingly driven by the lower recall by the young adults in the OP condition; post-hoc Tukey's HSD showed no significant differences between the two young adult conditions $p=.089, d=0.61$. $\mathrm{MP}=$ market-priced condition; $\mathrm{OP}=$ overpriced condition. 
Table 2

Analyses of variance for the Noun-Pair Lookup Task

\begin{tabular}{|c|c|c|c|c|c|}
\hline Statistical Test & $\mathrm{df}$ & $M S_{\text {Error }}$ & $F$ & $\eta_{G}^{2}$ & $p$ \\
\hline \multicolumn{6}{|l|}{ Accuracy } \\
\hline Age & 1,113 & 0.03 & 25.43 & .08 & $<.0001 *$ \\
\hline Condition & 1,113 & 0.03 & 0.52 & .002 & .47 \\
\hline Age $\mathrm{x}$ Condition & 1,113 & 0.03 & 3.52 & .01 & .06 \\
\hline Block & $8.66,978.82$ & 0.01 & 1.19 & .006 & .30 \\
\hline Age $\times$ Block & $8.66,978.82$ & 0.01 & 0.77 & .004 & .64 \\
\hline Condition x Block & $8.66,978.82$ & 0.01 & 0.42 & .002 & .92 \\
\hline Age $\mathrm{x}$ Condition $\mathrm{x}$ Block & $8.66,978.82$ & 0.01 & 1.19 & .006 & .30 \\
\hline \multicolumn{6}{|l|}{ Retrieval Use } \\
\hline Age & 1,113 & 1.04 & 98.57 & .36 & $<.0001^{*}$ \\
\hline Condition & 1,113 & 1.04 & 1.77 & .01 & .19 \\
\hline Age $\mathrm{x}$ Condition & 1,113 & 1.04 & 0.00 & $<.0001$ & .96 \\
\hline Block & $4.56,515.22$ & 0.12 & 107.07 & .24 & $<.0001 *$ \\
\hline Age $x$ Block & $4.56,515.22$ & 0.12 & 17.24 & .05 & $<.0001 *$ \\
\hline Condition x Block & $4.56,515.22$ & 0.12 & 2.08 & .006 & .07 \\
\hline Age $\mathrm{x}$ Condition $\mathrm{x}$ Block & $4.56,515.22$ & 0.12 & 1.09 & .003 & .36 \\
\hline \multicolumn{6}{|l|}{ Last block Retrieval Use } \\
\hline 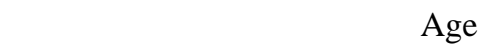 & 1,113 & 0.08 & 76.09 & .40 & $<.0001^{*}$ \\
\hline Condition & 1,113 & 0.08 & 4.87 & .04 & $.03 *$ \\
\hline Age $\mathrm{x}$ Condition & 1,113 & 0.08 & 0.61 & .005 & .43 \\
\hline \multicolumn{6}{|l|}{ Reaction Times } \\
\hline Age & 1,113 & 11464105.22 & 172.98 & .52 & $<.0001^{*}$ \\
\hline Condition & 1,113 & 11464105.22 & 1.32 & .008 & .25 \\
\hline Age $\mathrm{x}$ Condition & 1,113 & 11464105.22 & 0.00 & $<.0001$ & .95 \\
\hline Block & $4.95,558.82$ & 902930.37 & 164.59 & .29 & $<.0001^{*}$ \\
\hline Age $x$ Block & $4.95,558.82$ & 902930.37 & 2.26 & .006 & $.048 *$ \\
\hline Condition x Block & $4.95,558.82$ & 902930.37 & 1.43 & .004 & .21 \\
\hline Age $\mathrm{x}$ Condition $\mathrm{x}$ Block & $4.95,558.82$ & 902930.37 & 1.98 & .005 & .08 \\
\hline \multicolumn{6}{|l|}{ Recognition Memory } \\
\hline Age & 1,111 & 1.36 & 38.92 & .24 & $<.0001^{*}$ \\
\hline Condition & 1,111 & 1.36 & 2.79 & .02 & .10 \\
\hline Age $\mathrm{x}$ Condition & 1,111 & 1.36 & 0.02 & .0001 & .88 \\
\hline Block & 1,111 & 0.17 & 0.11 & $<.0001$ & .74 \\
\hline Age $x$ Block & 1,111 & 0.17 & 0.15 & .0001 & .70 \\
\hline Condition x Block & 1,111 & 0.17 & 0.00 & $<.0001$ & .97 \\
\hline Age $\mathrm{x}$ Condition $\mathrm{x}$ Block & 1,111 & 0.17 & 0.04 & $<.0001$ & .83 \\
\hline \multicolumn{6}{|c|}{ Retrieval Use compared to Recognition Memory } \\
\hline Age & 1,111 & 0.08 & 65.56 & .31 & $<.0001^{*}$ \\
\hline Condition & 1,111 & 0.08 & 4.21 & .03 & $.043 *$ \\
\hline Age $\mathrm{x}$ Condition & 1,111 & 0.08 & .26 & .002 & .61 \\
\hline Memory Type & 1,111 & 0.02 & 135.88 & .22 & $<.0001^{*}$ \\
\hline Age by Memory Type & 1,111 & 0.02 & 65.49 & .12 & $<.0001^{*}$ \\
\hline Condition x Memory Type & 1,111 & 0.02 & 3.45 & .007 & .07 \\
\hline Age x Condition x Memory Type & 1,111 & 0.02 & .79 & .002 & .37 \\
\hline \multicolumn{6}{|l|}{ Global Confidence } \\
\hline Age & 1,110 & 563.20 & 35.21 & .24 & $<.0001^{*}$ \\
\hline Condition & 1,110 & 563.20 & 0.24 & .002 & .62 \\
\hline Age $\mathrm{x}$ Condition & 1,110 & 563.20 & 3.38 & .02 & .07 \\
\hline
\end{tabular}

Note. $* p<.05$ 
Table 3

Analyses of variance for the Grocery-Price Lookup Task

\begin{tabular}{|c|c|c|c|c|c|}
\hline Statistical Test & df & $M S_{\text {Error }}$ & $F$ & $\eta_{G}^{2}$ & $p$ \\
\hline \multicolumn{6}{|l|}{ Accuracy } \\
\hline Age & 1,114 & 0.08 & 19.31 & .09 & $<.0001 *$ \\
\hline Condition & 1,114 & 0.08 & 1.60 & .008 & .21 \\
\hline Age $\mathrm{x}$ Condition & 1,114 & 0.08 & 5.31 & .03 & $.02 *$ \\
\hline Block & $10.75,1225.14$ & 0.01 & 2.58 & .010 & $.003^{*}$ \\
\hline Age $\times$ Block & $10.75,1225.14$ & 0.01 & 0.93 & .004 & .51 \\
\hline Condition x Block & $10.75,1225.14$ & 0.01 & 1.57 & .006 & .10 \\
\hline Age $\mathrm{x}$ Condition $\mathrm{x}$ Block & $10.75,1225.14$ & 0.01 & 2.38 & .009 & $.007 *$ \\
\hline \multicolumn{6}{|c|}{ 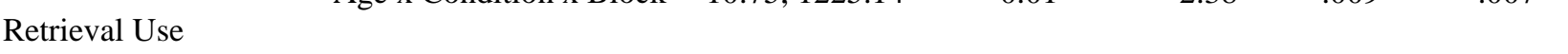 } \\
\hline Age & 1,114 & 1.00 & 18.69 & .09 & $<.0001 *$ \\
\hline Condition & 1,114 & 1.00 & 46.22 & .21 & $<.0001 *$ \\
\hline Age $\mathrm{x}$ Condition & 1,114 & 1.00 & 0.38 & .002 & .54 \\
\hline Block & $4.87,554.85$ & 0.12 & 102.97 & .25 & $<.0001 *$ \\
\hline Age $\mathrm{x}$ Block & $4.87,554.85$ & 0.12 & 1.76 & .006 & .12 \\
\hline Condition x Block & $4.87,554.85$ & 0.12 & 6.04 & .02 & $<.0001 *$ \\
\hline Age $\mathrm{x}$ Condition $\mathrm{x}$ Block & $4.87,554.85$ & 0.12 & 0.53 & .002 & .75 \\
\hline \multicolumn{6}{|l|}{ Last block Retrieval Use } \\
\hline 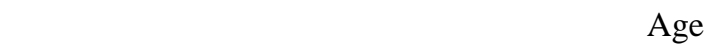 & 1,114 & 0.09 & 8.54 & .07 & $.004 *$ \\
\hline Condition & 1,114 & 0.09 & 26.26 & .17 & $<.0001 *$ \\
\hline Age $\mathrm{x}$ Condition & 1,114 & 0.09 & 1.34 & .01 & .25 \\
\hline \multicolumn{6}{|l|}{ Retrieval Use with NPLT retrieval use covariate } \\
\hline Age & 1,107 & 0.84 & 0.29 & .002 & .59 \\
\hline Condition & 1,107 & 0.84 & 32.71 & .16 & $<.0001 *$ \\
\hline NPLT retrieval use & 1,107 & 0.84 & 13.07 & .07 & $.0005^{*}$ \\
\hline Age $\mathrm{x}$ Condition & 1,107 & 0.84 & 0.06 & .0003 & .81 \\
\hline Age $x$ NPLT retrieval use & 1,107 & 0.84 & 0.04 & .0002 & .84 \\
\hline Condition $\mathrm{x}$ NPLT retrieval use & 1,107 & 0.84 & 0.40 & .002 & .53 \\
\hline Age $\mathrm{x}$ Condition $\mathrm{x}$ NPLT retrieval use & 1,107 & 0.84 & 0.78 & .004 & .38 \\
\hline Block & $5.34,571.20$ & 0.10 & 52.60 & .16 & $<.0001 *$ \\
\hline Age $x$ Block & $5.34,571.20$ & 0.10 & 1.41 & .005 & .22 \\
\hline Condition x Block & $5.34,571.20$ & 0.10 & 3.41 & .01 & $.004 *$ \\
\hline NPLT retrieval use $\mathrm{x}$ Block & $5.34,571.20$ & 0.10 & 4.79 & .02 & $.0002 *$ \\
\hline Age $\mathrm{x}$ Condition $\mathrm{x}$ Block & $5.34,571.20$ & 0.10 & 0.49 & .002 & .79 \\
\hline Age $x$ NPLT retrieval use $x$ Block & $5.34,571.20$ & 0.10 & 0.58 & .002 & .73 \\
\hline Age $\mathrm{x}$ Condition $\mathrm{x}$ NPLT retrieval use $\mathrm{x}$ Block & $5.34,571.20$ & 0.10 & 1.01 & .004 & .41 \\
\hline \multicolumn{6}{|c|}{ Last block Retrieval Use with NPLT retrieval use covariate } \\
\hline Age & 1,107 & 0.08 & 0.02 & .0002 & .90 \\
\hline Condition & 1,107 & 0.08 & 18.10 & .14 & $<.0001 *$ \\
\hline NPLT retrieval use & 1,107 & 0.08 & 9.22 & .08 & $.003^{*}$ \\
\hline Age $\mathrm{x}$ Condition & 1,107 & 0.08 & 0.24 & .002 & .63 \\
\hline Age $x$ NPLT retrieval use & 1,107 & 0.08 & 0.46 & .004 & .50 \\
\hline Condition $\mathrm{x}$ NPLT retrieval use & 1,107 & 0.08 & 2.46 & .02 & .12 \\
\hline Age $\mathrm{x}$ Condition $\mathrm{x}$ NPLT retrieval use & 1,107 & 0.08 & 0.57 & .005 & .45 \\
\hline \multicolumn{6}{|l|}{ Reaction Times } \\
\hline Age & 1,114 & 4312482.87 & 145.55 & .44 & $<.0001 *$ \\
\hline Condition & 1,114 & 4312482.87 & 28.57 & .08 & $<.0001 *$ \\
\hline Age $\mathrm{x}$ Condition & 1,114 & 4312482.87 & 1.13 & .003 & .29 \\
\hline Block & $7.48,852.57$ & 328365.41 & 116.75 & .17 & $<.0001 *$ \\
\hline Age x Block & $7.48,852.57$ & 328365.41 & 3.80 & .007 & $.0003 *$ \\
\hline Condition x Block & $7.48,852.57$ & 328365.41 & 3.04 & .005 & $.003 *$ \\
\hline Age $\mathrm{x}$ Condition $\mathrm{x}$ Block & $7.48,852.57$ & 328365.41 & 1.58 & .003 & .13 \\
\hline
\end{tabular}




\begin{tabular}{|c|c|c|c|c|c|}
\hline \multicolumn{6}{|l|}{ Recognition Memory } \\
\hline Condition & 1,114 & 1.26 & 51.66 & .28 & $<.0001 *$ \\
\hline Age & 1,114 & 1.26 & 1.46 & .01 & .23 \\
\hline Condition $\mathrm{x}$ Age & 1,114 & 1.26 & 0.49 & .004 & .49 \\
\hline Block & 1,114 & 0.22 & 0.03 & $<.0001$ & .85 \\
\hline Condition x Block & 1,114 & 0.22 & 2.09 & .003 & .15 \\
\hline Age x Block & 1,114 & 0.22 & 0.44 & .0006 & .51 \\
\hline Condition $\mathrm{x}$ Age $\mathrm{x}$ Block & 1,114 & 0.22 & 0.00 & $<.0001$ & .97 \\
\hline \multicolumn{6}{|l|}{ Retrieval Use compared to Recognition Memory } \\
\hline Age & 1,114 & 0.07 & 8.05 & .04 & $<.005^{*}$ \\
\hline Condition & 1,114 & 0.07 & 40.82 & .19 & $<.0001 *$ \\
\hline Age $\mathrm{x}$ Condition & 1,114 & 0.07 & 1.49 & .01 & .22 \\
\hline Memory Type & 1,114 & 0.04 & 75.95 & .19 & $<.0001 *$ \\
\hline Age by Memory Type & 1,114 & 0.04 & 7.17 & .02 & $.009 *$ \\
\hline Condition x Memory Type & 1,114 & 0.04 & 7.42 & .02 & $.0008^{*}$ \\
\hline Age x Condition x Memory Type & 1,114 & 0.04 & 0.85 & .002 & .36 \\
\hline \multicolumn{6}{|l|}{ Global Confidence } \\
\hline Age & 1,114 & 683.78 & 0.01 & $<.0001$ & .92 \\
\hline Condition & 1,114 & 683.78 & 21.34 & .16 & $<.0001 *$ \\
\hline Age $\mathrm{x}$ Condition & 1,114 & 683.78 & 0.45 & .004 & .50 \\
\hline
\end{tabular}

Note. $* p<.05$ 
Table 4

Pearson Correlations of Retrieval Use between the Noun-Pair Lookup Task and the GroceryPrice Lookup Task

\begin{tabular}{lcccc}
\hline & \multicolumn{2}{c}{ Non-retrievers excluded } & \multicolumn{2}{c}{ Non-retrievers included } \\
\cline { 2 - 4 } \multicolumn{1}{c}{ Sample } & $r[\mathrm{CI}]$ & $\mathrm{df}$ & $r[\mathrm{CI}]$ & $\mathrm{df}$ \\
\hline $\begin{array}{l}\text { Whole } \\
\text { sample }\end{array}$ & $.29[.11, .46]$ & 103 & $.51[.36, .63]$ & 113 \\
$\begin{array}{l}\text { Young } \\
\text { adults }\end{array}$ & $-.02[-.28, .25]$ & 53 & $.38[.13, .58]$ & 55 \\
Older adults & $.33[.06, .56]$ & 48 & $.51[.29, .68]$ & 56 \\
\hline
\end{tabular}

Note . $[\mathrm{CI}]=95 \%$ confidence interval around the correlation estimate; $r=$ Pearson correlation.

Non-retrievers were participants who did not endorse the retrieval strategy in the final block of practice in both tasks. Non-retrievers included two young adults from the overpriced condition, two older adults from the market-priced condition, and six older adults from the overpriced condition. The power to find a result as large, or larger than the effect sizes we obtained at the given sample size assuming that the effect sizes were the true population mean, and that alternative hypothesis is true is $.87, .05, .67$, for the correlations with non-retrievers excluded, in descending order, and $.99, .98, .82$, for the correlations including non-retrievers, in descending order. 
Table 5

Post-Task Questionnaire means for the Grocery-Price and Noun-Pair Lookup Tasks

\begin{tabular}{|c|c|c|c|}
\hline Dependent Variable & Task & YAs & OAs \\
\hline \multicolumn{4}{|l|}{ JOLs } \\
\hline & NPLT & $90(2.89)^{x}$ & $59(2.89)^{\mathbf{y}}$ \\
\hline & GPLT: MP & $83(4.51)^{\mathrm{a}}$ & $79(4.43)^{\mathrm{a}}$ \\
\hline & GPLT: OP & $57(4.51)^{b}$ & $53(4.43)^{b}$ \\
\hline \multicolumn{4}{|l|}{ Cued Recall } \\
\hline & NPLT & $10(.03)^{x}$ & $5(.003)^{\mathbf{y}}$ \\
\hline & GPLT: MP & $10(.41)^{\mathrm{a}}$ & $9(.45)^{\mathrm{a}}$ \\
\hline & GPLT: OP & $6(.69)^{b}$ & $5(.7)^{b}$ \\
\hline \multicolumn{4}{|l|}{ Estimated total pairs } \\
\hline memorized & NPLT & $10(.33)^{x}$ & $7(.34)^{\mathbf{y}}$ \\
\hline & GPLT: MP & $9(.51)^{\mathrm{a}}$ & $8(.44)^{\mathrm{a}}$ \\
\hline & GPLT: OP & $6(.48)^{b}$ & $5(.53)^{b}$ \\
\hline \multicolumn{4}{|l|}{ Global confidence } \\
\hline & NPLT & $85(2.13)^{x}$ & $58(3.98)^{\mathbf{y}}$ \\
\hline & GPLT: MP & $74(3.48)^{a}$ & $71(4.19)^{\mathrm{a}}$ \\
\hline & GPLT: OP & $48(5.04)^{b}$ & $52(6.09)^{b}$ \\
\hline \multicolumn{4}{|l|}{ Estimated memory } \\
\hline \multirow[t]{3}{*}{ strategy usage } & NPLT & $79(2.80)^{x}$ & $33(4.06)^{\mathbf{y}}$ \\
\hline & GPLT: MP & $78(3.52)^{a}$ & $56(4.80)^{\mathbf{b}}$ \\
\hline & GPLT: OP & $48(5.59)^{b}$ & $27(4.53)^{\mathbf{c}}$ \\
\hline \multicolumn{4}{|l|}{ Effort learning pairs } \\
\hline & NPLT & $43(3.90)^{x}$ & $48(3.38)^{x}$ \\
\hline & GPLT: MP & $50(6.28)^{\mathrm{a}}$ & $55(4.31)^{\mathrm{a}}$ \\
\hline & GPLT: OP & $66(4.59)^{a}$ & $55(5.25)^{\mathrm{a}}$ \\
\hline \multicolumn{4}{|l|}{ Difficulty of task } \\
\hline & NPLT & $25(3.01)^{x}$ & $38(4.08)^{\mathbf{y}}$ \\
\hline & GPLT: MP & $49(5.47)^{\mathrm{a}}$ & $38(4.24)^{\mathrm{a}}$ \\
\hline & GPLT: OP & $66(4.32)^{b}$ & $60(4.59)^{b}$ \\
\hline \multicolumn{4}{|l|}{ Difficulty of GPLT } \\
\hline compared to NPLT (0 & GPLT: MP & $68(5.17)^{\mathrm{a}}$ & $27(4.48)^{\mathbf{b}}$ \\
\hline easier; 100, harder) & GPLT: OP & $78(5.31)^{\mathrm{a}}$ & $59(5.21)^{\mathrm{a}}$ \\
\hline
\end{tabular}

Note. Standard errors are displayed in parentheses. Different superscripts designate significant differences using Tukey's HSD. Comparisons were not made between tasks. All dependent variables ranged from 0-100 except for cued recall and estimated total pairs memorized, which ranged from 0-12. See Table S4 and S5 for the full list of Post-Task Questionnaire items. YAs = Young adults; OAs = Older adults; NPLT = Noun-Pair Lookup Task; GPLT: MP = GroceryPrice Lookup Task: market-priced; GPLT: OP = Grocery-Price Lookup Task: overpriced. 
Table 6

Correlations between end retrieval use and metacognitive and memory measures

\begin{tabular}{|c|c|c|c|c|}
\hline \multirow[b]{2}{*}{ PTQ } & \multicolumn{2}{|c|}{ GPLT } & \multicolumn{2}{|c|}{ NPLT } \\
\hline & YAs & OAs & YAs & OAs \\
\hline $\begin{array}{l}\text { Estimated number of } \\
\text { pairs memorized }\end{array}$ & $.47[.22, .66] * *$ & $.59[.40, .74] * *$ & $.52[.29, .69] * *$ & $.50[.27, .68] * *$ \\
\hline Global confidence & $.47[.22, .66] * *$ & $.57[.37, .72] * *$ & $.31[.06, .53] *$ & $.36[.11, .58] *$ \\
\hline $\begin{array}{l}\text { Estimated use of } \\
\text { retrieval strategy }\end{array}$ & $.42[.17, .63] * *$ & $.71[.56, .82] * *$ & $.36[.11, .56] *$ & $.61[.40, .75] * *$ \\
\hline Effort memorization & $-.23[-.48, .05]$ & $.07[-.18, .32]$ & $-.06[-.32, .19]$ & $.39[.14, .60] * *$ \\
\hline Difficulty of task & $-.40[-.61,-.15] *$ & $-.25[-.48, .01]$ & $-.07[-.33, .19]$ & $.02[-.25, .29]$ \\
\hline GPLT vs NPLT & $-.19[-.44, .09]$ & $-.36[-.56,-.12] *$ & & \\
\hline JOLs & $.56[.35, .73] * *$ & $.67[.48, .79] * *$ & $.49[.25, .67] * *$ & $.37[.05, .61] *$ \\
\hline Cued-Recall & $.54[.32, .71] * *$ & $.68[.48, .81] * *$ & $.42[.17, .62] * *$ & $.55[.28, .74] * *$ \\
\hline$d^{\prime}$ & $.57[.37, .72] * *$ & $.62[.43, .75] * *$ & $.79[.66, .87] * *$ & $.67[.50, .79] * *$ \\
\hline
\end{tabular}

Note. $95 \%$ Confidence intervals are noted in brackets. Different alpha thresholds were set between the Grocery-Price Lookup Task and Noun-Pair Lookup Task Post-Task Questionnaire correlations due to differing numbers of correlations calculated; the full suite of correlations can be found in Table S3 in the Supplemental Materials. For the Grocery-Price Lookup Task correlations, alpha was set to .002 (.05/24); for the Noun-Pair Lookup Task correlations, alpha was set to $.00315(.05 / 16)$. Correlations meeting traditional significance are noted. GPLT $=$ Grocery-Price Lookup Task; NPLT = Noun-Pair Lookup Task; Global confidence $=$ self-rated confidence in using the memory strategy; GPLT vs NPLT = relative difficulty of the GroceryPrice Lookup Task compared to the Noun-Pair Lookup Task; JOLs = Judgments of Learning. $* p<.05 * * p<$ alpha threshold 


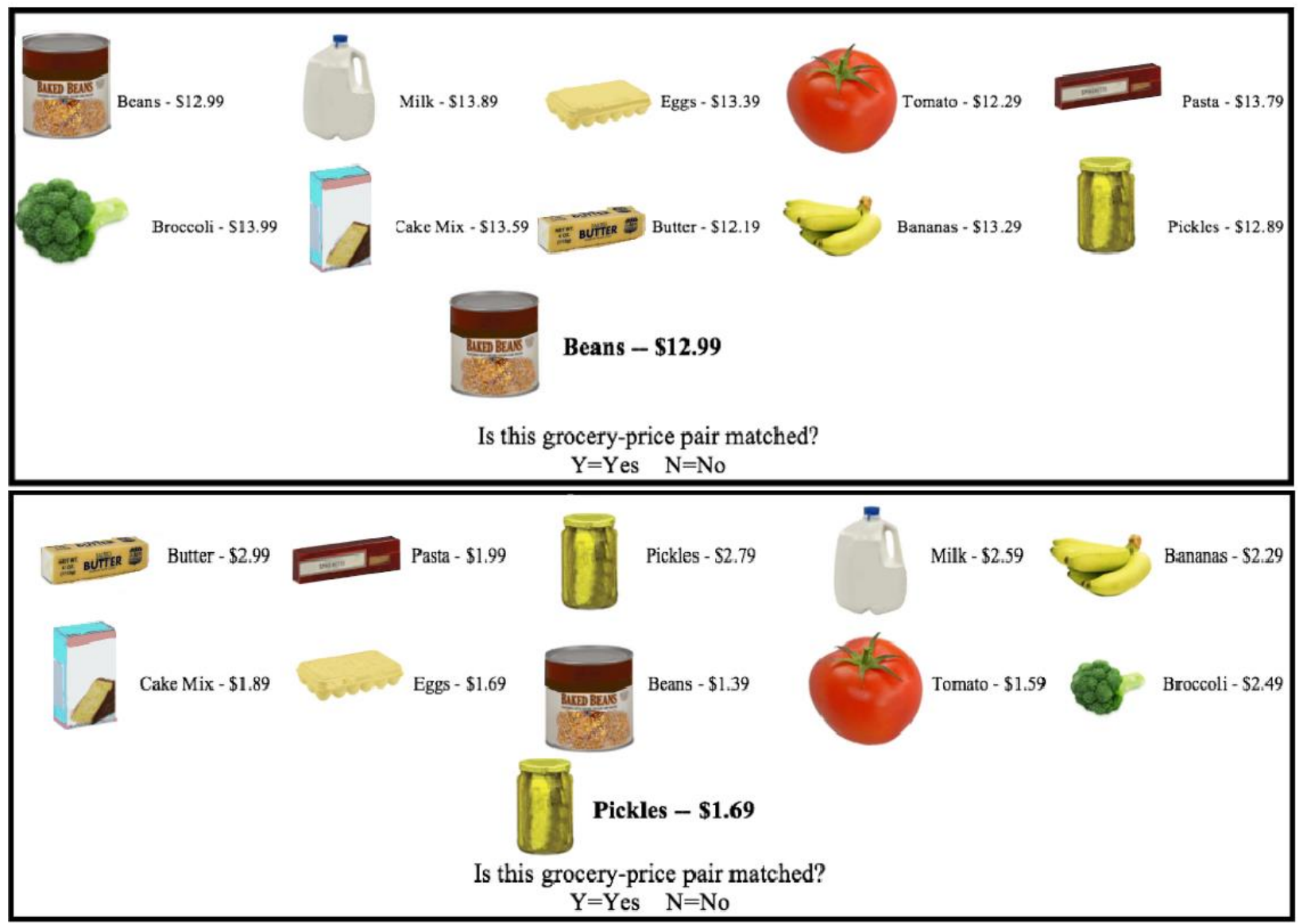

Figure 1. Example of the Grocery-Price Lookup Task. The top panel represents the overpriced condition on a match trial, and the bottom panel represents the market-priced condition on a mismatch trial. 


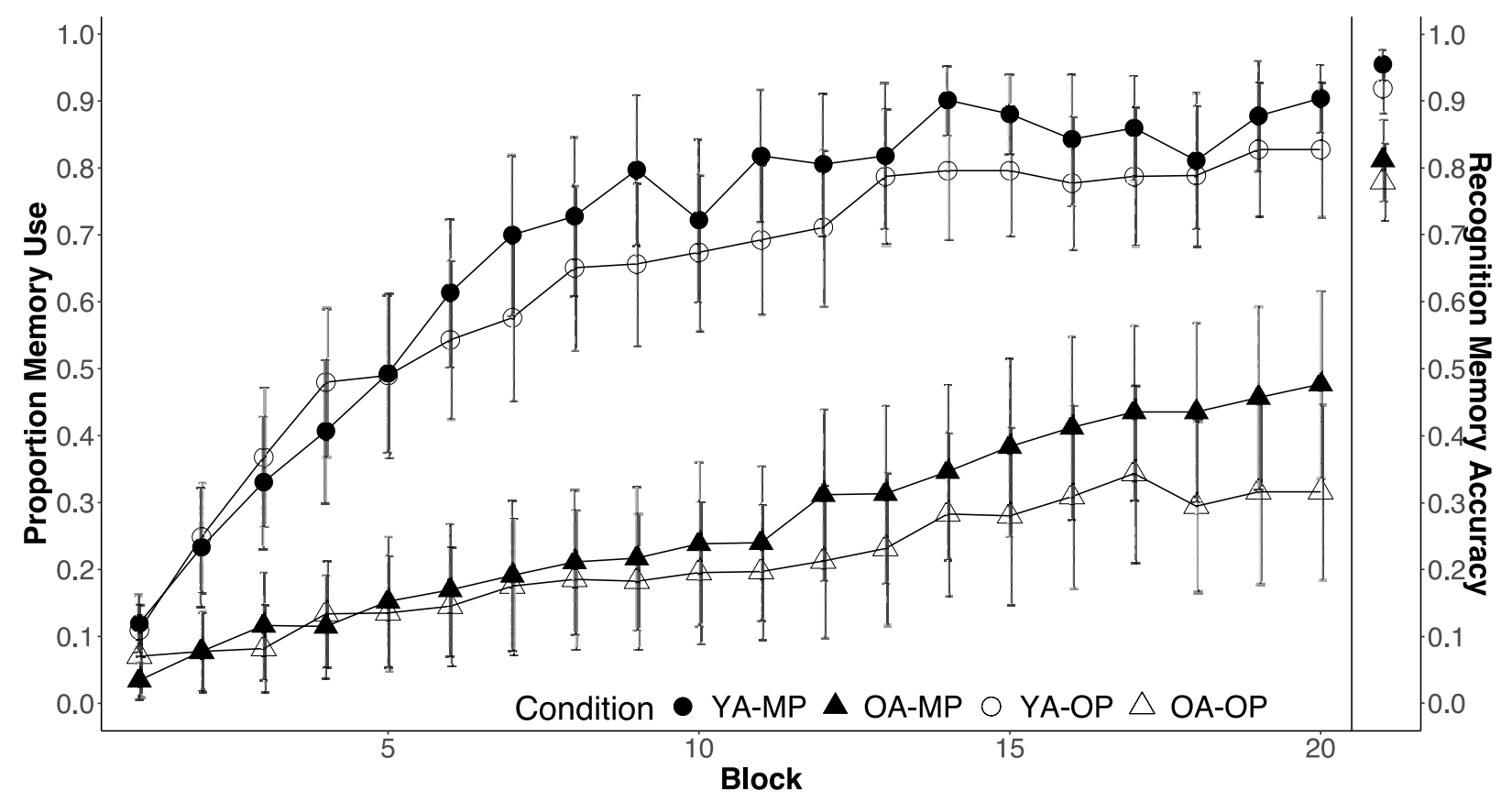

Figure 2. Endorsement of the Retrieval Strategy in the Noun-Pair Lookup Task. The panels are separated by age and condition, followed by recognition memory. Condition was not meaningful for this task but is included in the figure because there were differences in retrieval use between the conditions, although they were not statistically significant. The first block of recognition memory data is plotted following the vertical line. Only the age difference was significant for recognition memory. Error bars are 95\% CI. MP = market-priced; OP = overpriced. 


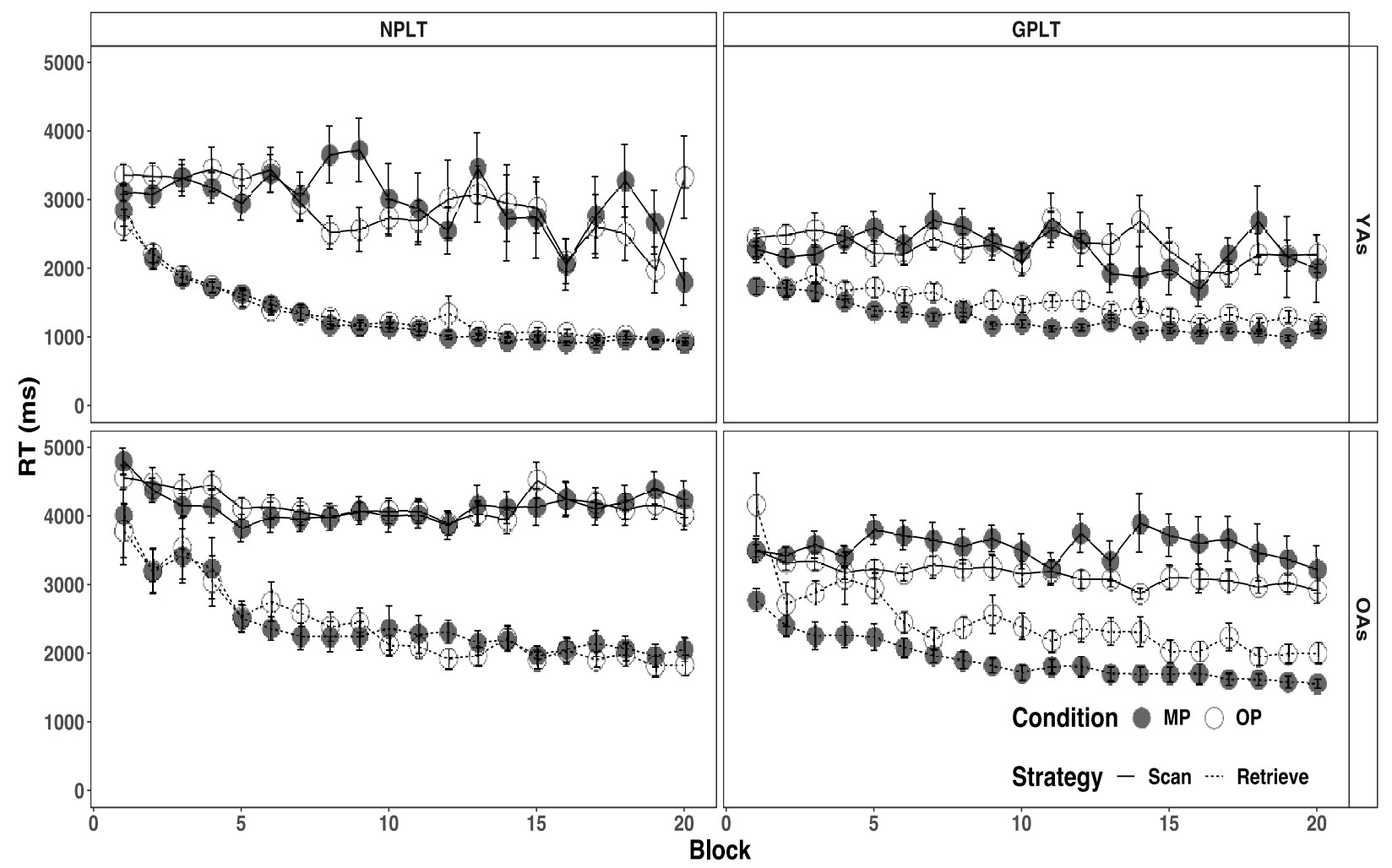

Figure 3. Reaction Times for the Scanning and Retrieval Strategies in the Noun-Pair Lookup Task and the Grocery-Price Lookup Task. The panels are separated by task and age group to examine condition differences within age group, although the condition difference was not meaningful in the Noun-Pair Lookup Task. Retrieval times improved with practice. Because of changing rates of strategy endorsements, estimates in earlier blocks for scanning are more reliable than later blocks, e.g., the young adult scanning values in the $20^{\text {th }}$ block of the Noun-Pair Lookup Task are based on the medians from six participants each; estimates in later blocks for retrieval are more reliable than earlier blocks, e.g., the young adult retrieval values in the $20^{\text {th }}$ block of the Noun-Pair Lookup Task are based on the medians from 30 participants each. NPLT = Noun-Pair Lookup Task; GPLT = Grocery-Price Lookup Task; YAs = Young adults; OAs = Older adults; $\mathrm{MP}=$ Market-priced; $\mathrm{OP}=$ Overpriced. Error bars are $\pm 1 \mathrm{SEM}$. 


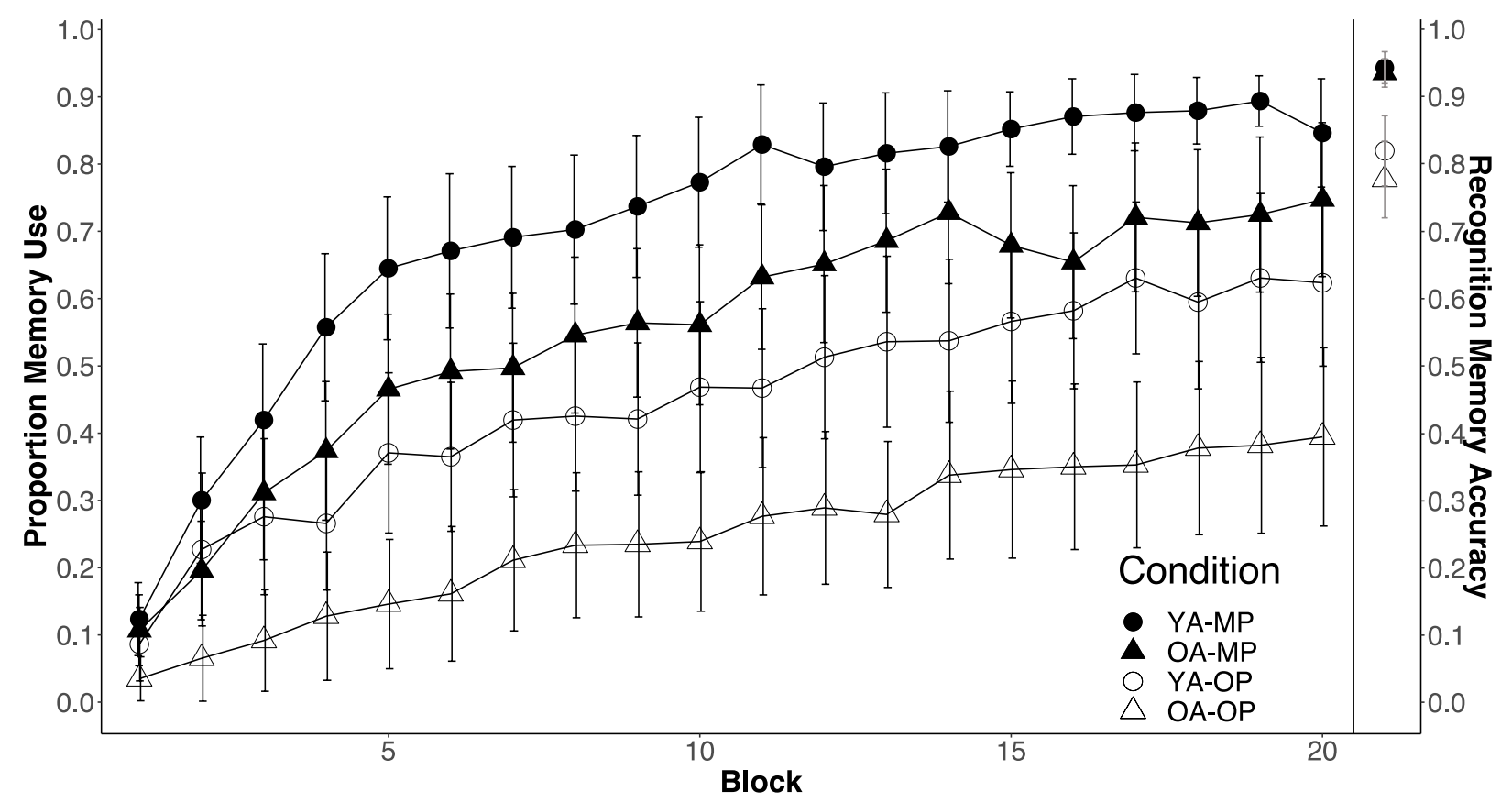

Figure 4. Endorsement of the Retrieval Strategy in the Grocery-Price Lookup Task. Separate lines and shapes indicating age group and condition, followed by the first block of recognition memory accuracy after the vertical line. By the final block, older adults in the market-priced condition were equivalent with young adults in the market-priced condition, and young adults in the overpriced condition. Only condition differences were significant in recognition memory, where the market-priced group performed better than the overpriced group. MP $=$ Market-priced condition; OP = Overpriced condition. Error bars are 95\% CI. 